\title{
Lifelike Anterior Composites
}

\author{
Ratnadeep Patil ${ }^{*}$
}

\section{Introduction}

Direct composite resin restorations can be a viable treatment option when an esthetic restoration is desired especially in case of uncomplicated tooth fractures. ${ }^{1,2}$ and standard veneer preparations for altering the shape and size of the existing anterior teeth. In the past the outcome of direct resin was compromised as they poorly reproduced the optical properties of natural teeth. Recent advances in adhesion technology, material properties and better understanding of optical properties of the natural tooth, has helped achieve better vitality, character and depth of a restoration. The direct resin buildup restoration based on contemporary layering technique allows clinicians to provide conservative treatment and a virtually imperceptible blend with adjacent tooth structures. ${ }^{3}$

\section{Shade judgment}

Shade is analyzed before tooth preparation and thereafter evaluated for every layer of composite. Shade selection involves visual comparison between the natural teeth and standard colored dental shade guides by the dentist ${ }^{8}$. It does not imply that the same shade composite will give us the desired outcome as the inherent opacity and the layer thickness will determine shade outcome. Shade matching, on the contrary, is highly technical process with unpredictable outcome since it depends on individual skill and knowledge8. It has to be an integral part of the layering technique.

Dentin is an opaque and fluorescent tissue and is responsible for the hue and chroma of the tooth by reflecting the light through the enamel. Enamel is a translucent and opalescent tissue and determines the value of the tooth. ${ }^{3,6}$

\section{Composite layering}

Composite layering done with the anatomic stratification technique helps reproduce natural

\footnotetext{
* The author is a graduate from Bombay University with a Private practice in Mumbai, since 1988 with special interest and expertise in Esthetic and Implant Dentistry. He is also a Diplomate, International College of Oral Implantologists and author of the clinical textbook on esthetic dentistry titled 'Esthetic Dentistry - An Artist's Science'. At present he is pursuing his Phd from Utrecht University.

(The author wishes to aknowledge the contribution of Dr. Anjali Dilbaghi)
}

appearance of enamel and dentin. Every layer has different shades and opacities when stratified, giving a "polychromatic effect" with a more realistic depth of color by creating an illusion of the way light is reflected, refracted, transmitted and absorbed to simulate that of dentin and enamel.

Though an exact recipe cannot be given since shade layering would vary from case to case, the general rule followed in anatomic stratification are-

1. Replace Palatal/lingual wall with an opaque composites. Since they have higher color saturation, when light strikes the optically dense layer, more light is reflected back to the eyes and thus contributes to the hue and chroma by optically replacing dentin. ${ }^{6,7}$

2. Use thin increments and observe shade after every layer is cured so that the shade of the next layer can be planned. Another advantage of this technique is that it minimizes the negative effects of shrinkage by creating small incremental shrinkage. ${ }^{5}$

3. Use translucent composites to encapsulate the inner dentin core. This alters the quantity and quality of the light reflected and thus decides the value of the restoration by optically replacing enamel in the restoration. ${ }^{6,7}$

\section{Case 1}

A 19 year-old male patient reported with fractured upper left central incisor and chipped surface of upper right central incisor (Figure 1-C1) due to a sports injury. Radiographic examination and cold test did not reveal any pulpal damage.

Shade was determined to be A3 using the Tetric N Ceram shade guide system. The patient being young, the incisal edge displayed translucency and incisal mamelons (Figure 1-C1)Occlusal view (Figure 2-C1) of the fractured teeth reveals the difference in opacity and translucency of dentin and enamel in \#21.

In \#11 a $1 \mathrm{~mm}$ bevel was placed along the margin of the chipped enamel surface (Figure 3-C1). An envelope preparation design extending $2 \mathrm{~mm}$ with a $1 \mathrm{~mm}$ bevel was prepared on the facial surface of \#21(Figure 3-C1,4C1). On the palatal surface of \#21 a rounded butt margin was prepared. (Figure 4-C1)

The cavity preparation was disinfected using a $2 \%$ chlorhexidine antibacterial solution. Etching was done for 15 seconds using $37 \%$ phosphoric acid (Figure 5$\mathrm{C} 1)$; the etchant was removed, and the tooth surface 


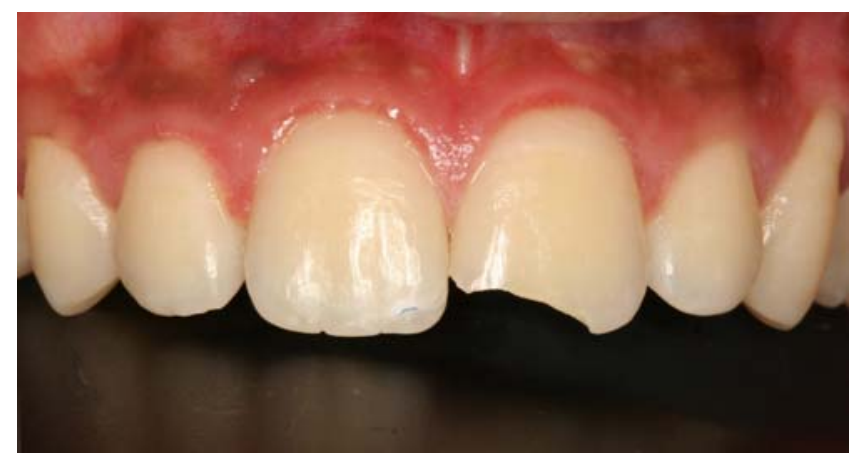

Figure 1-C1

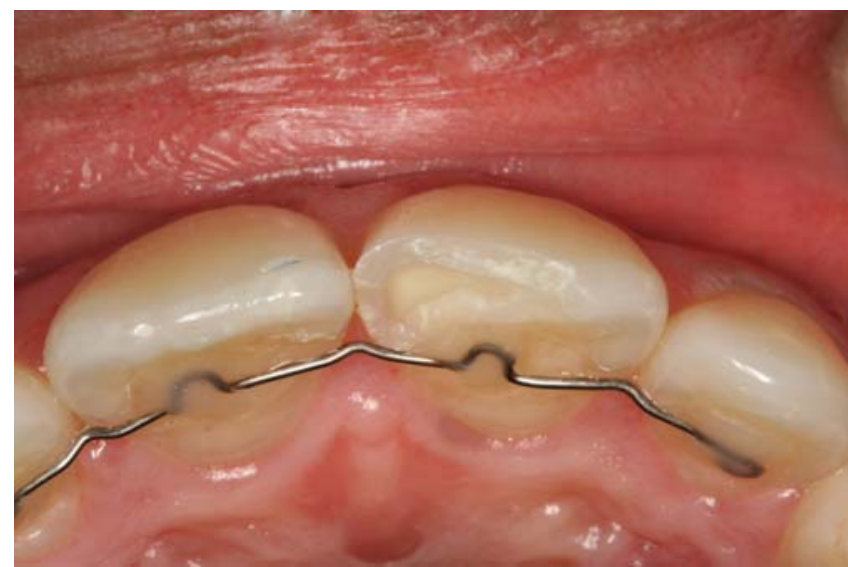

Figure 2-C1

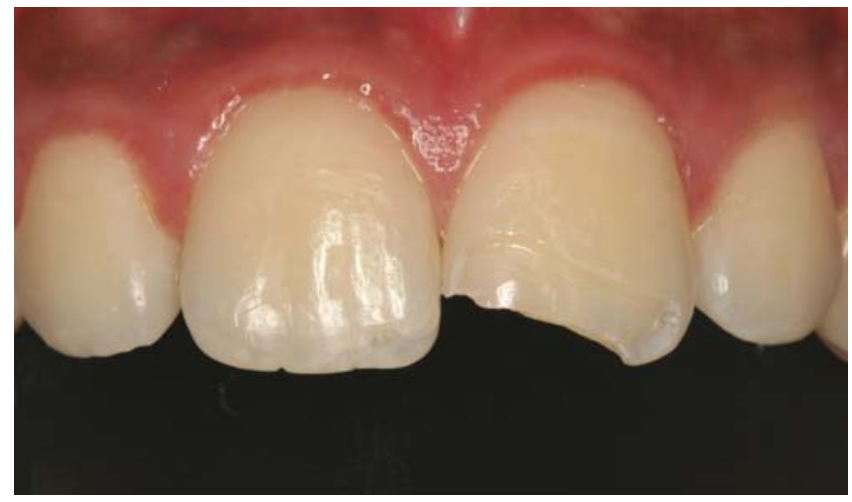

Figure $3-\mathrm{C} 1$

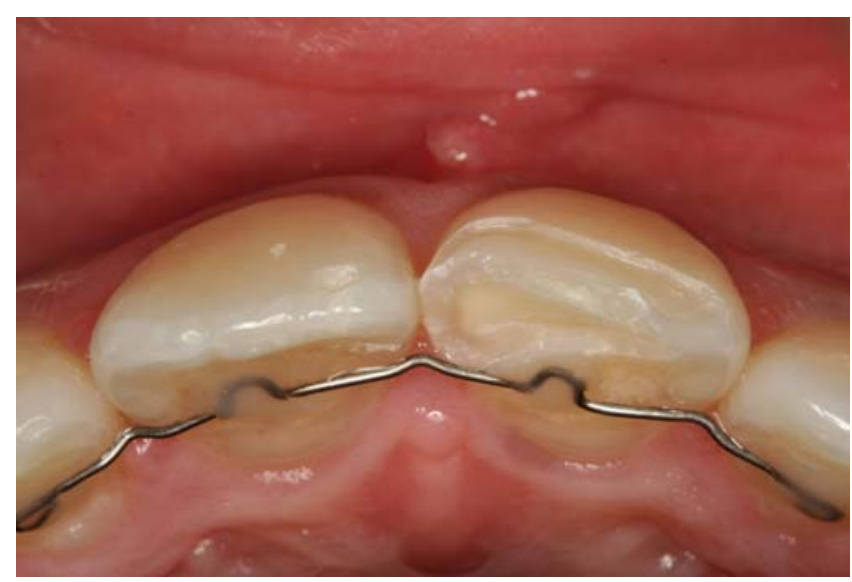

Figure 4-C1

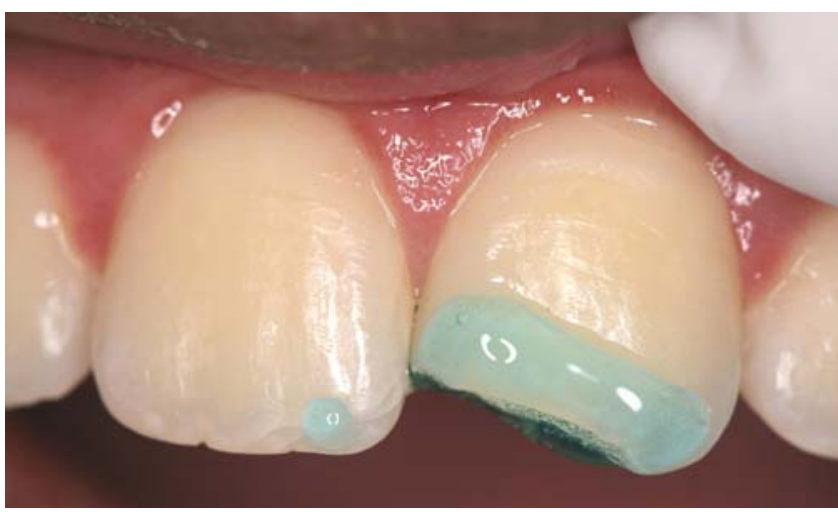

Figure 5-C1

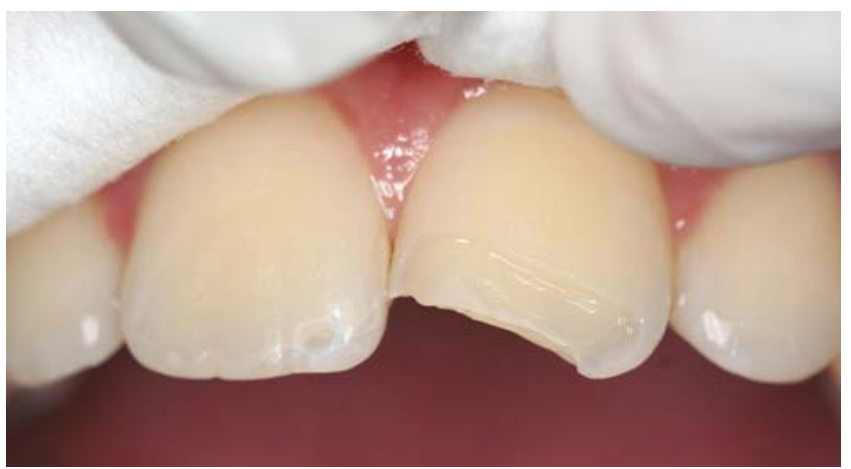

Figure 6-C1

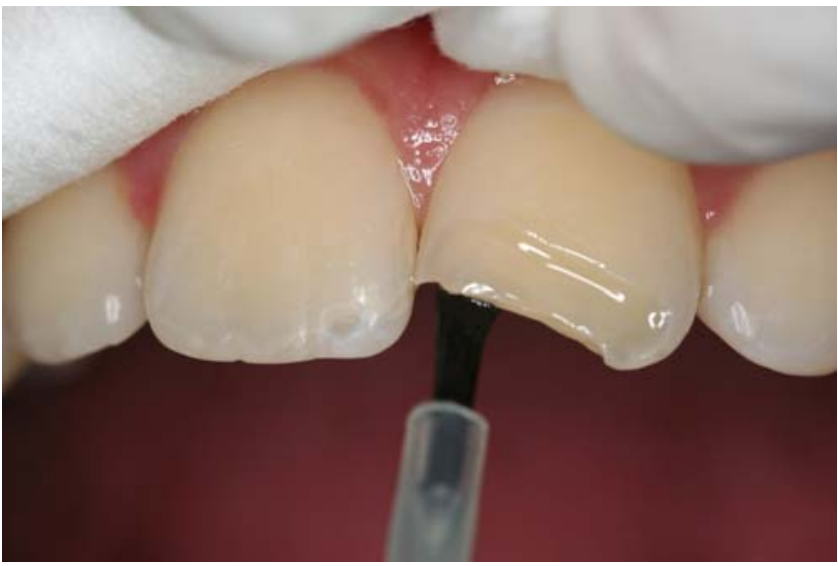

Figure $7-\mathrm{C} 1$

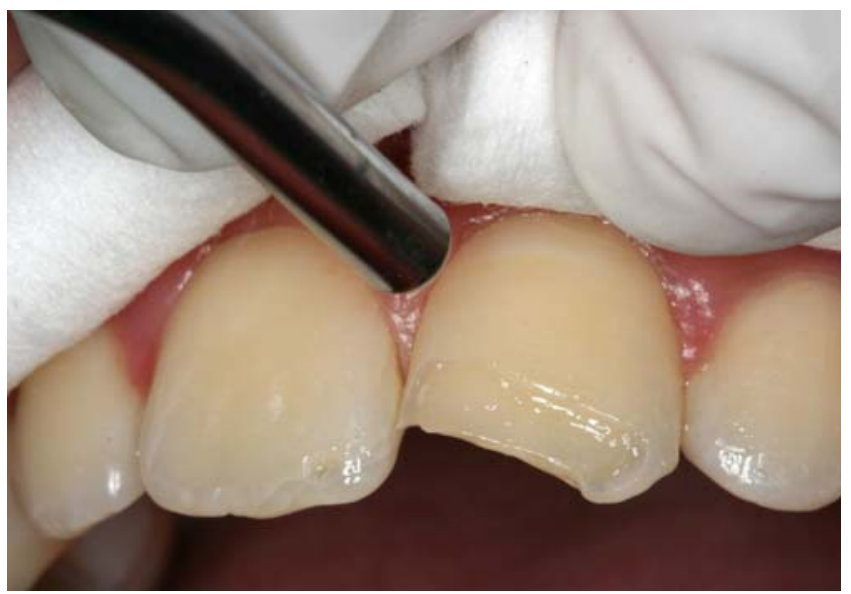

Figure 8-C1 
rinsed with water spray for 30 seconds followed by air drying taking care not to excessively dry the tooth surface. (Figure 6-C1) A fifth-generation nano optimized adhesive system (Tetric N-bond) was placed in the preparation and agitated for 10 seconds, then, gently air thinned (Figure 7-C1,8-C1), and polymerized for 20 seconds (Figure 9-C1).

In this case a nano composite resin system (Tetric NCeram) was selected as the material of choice to restore these teeth. Stratification was initiated with a thin layer (Figure 10-C1) of flowable resin placed in the line anglies of the preparation. ). A metal matrix strip was placed interdentally and a triangular-shaped,

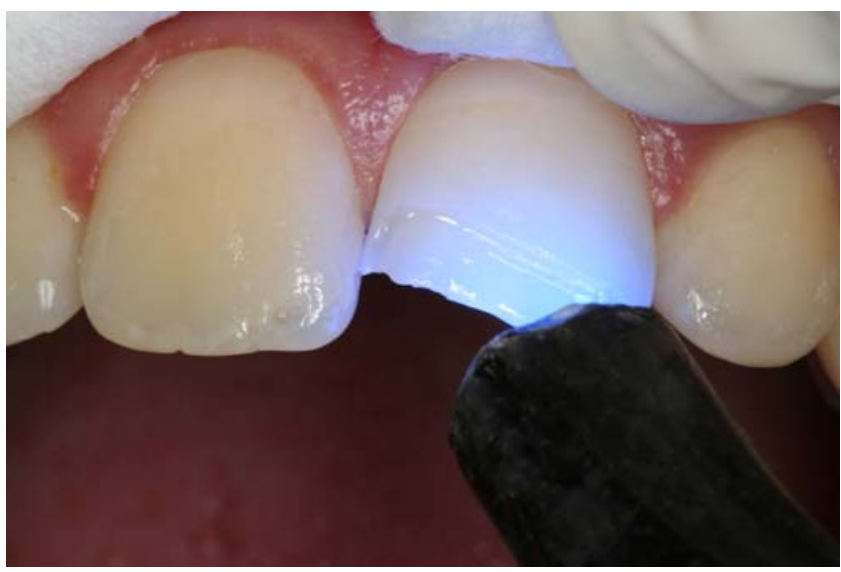

Figure 9-C1

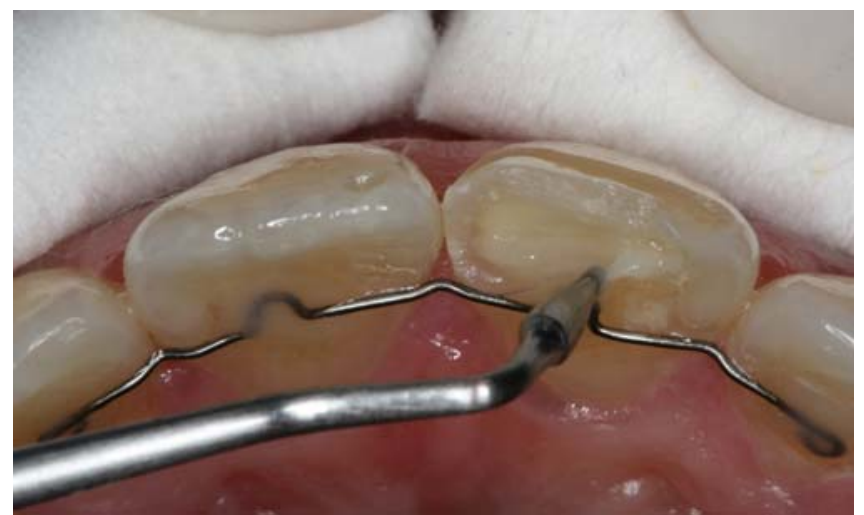

Figure $10-\mathrm{C} 1$

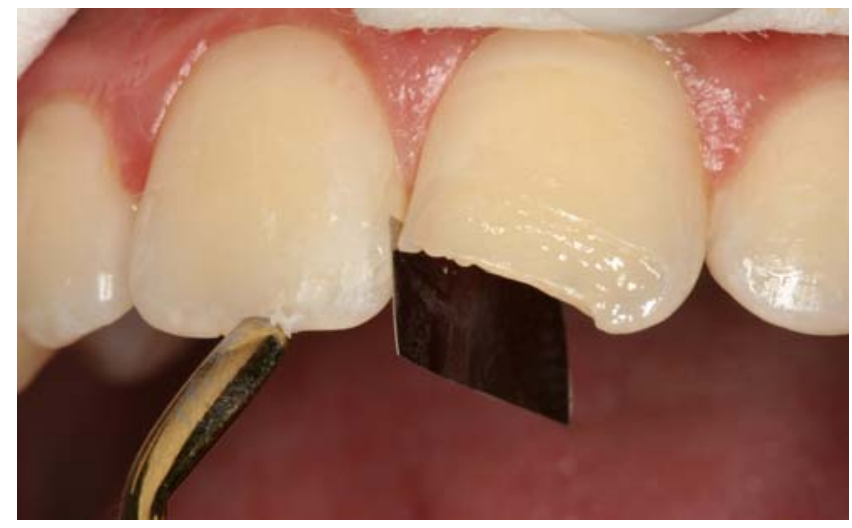

Figure $11-\mathrm{C} 1$ mesioincisal layer of the A3 body shade was placed and sculpted to reconstruct the proximal surface of \#11 (Figure 11-C1) Thereafter 1-mm of Bleach light shade was placed and cured to replicate the opaque dentin layer (Figure 12-C1, 13-C1, 14-C1)

Next increments of A3 enamel shades were layered (Figure 15-C1, 16-C1) with a long bladed instrument and texture lines created with a sable brush (Figure 17-C1) before curing. The mamelon effect was completed using the highly translucent incisal shade (Artemis) at the incisolingual matrix and two notches were placed to duplicate the external contours of the mamelons.

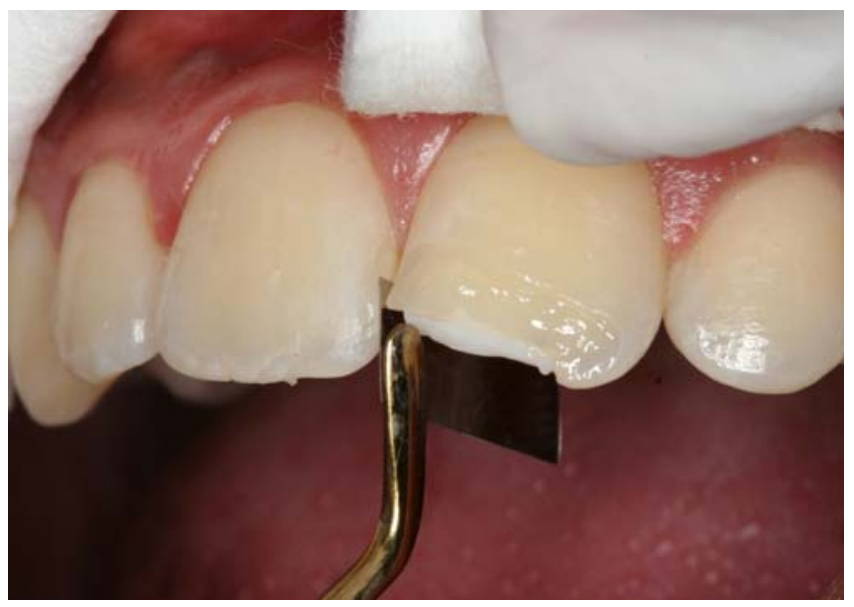

Figure 12-C1

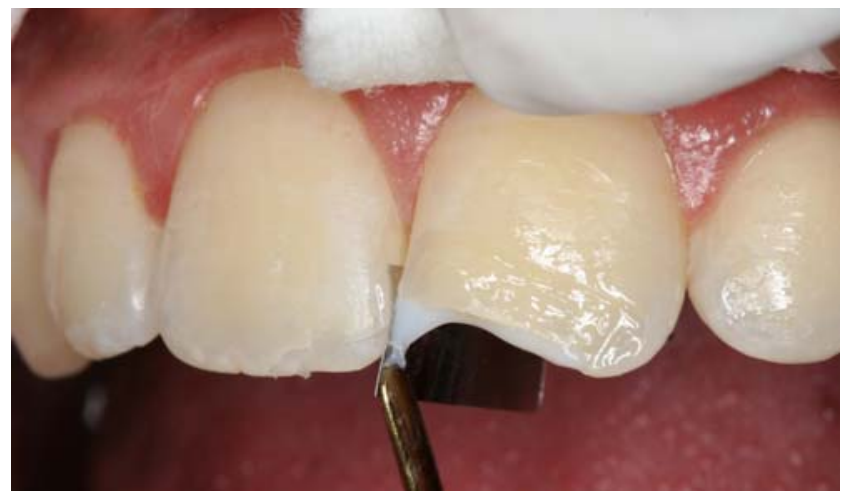

Figure 13-C1

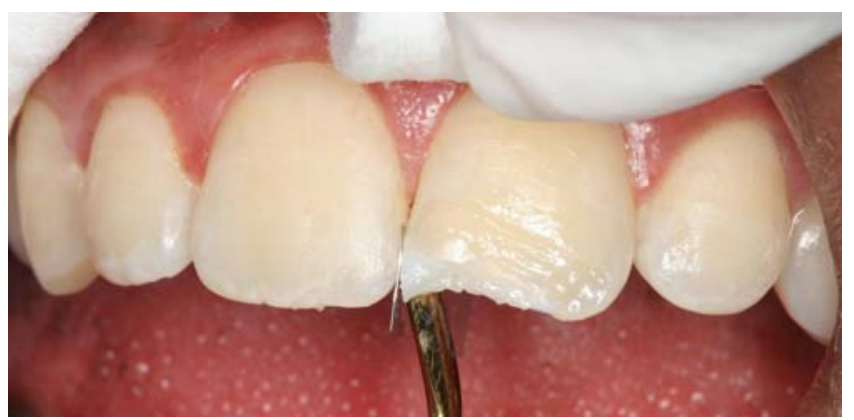

Figure 14-C1 


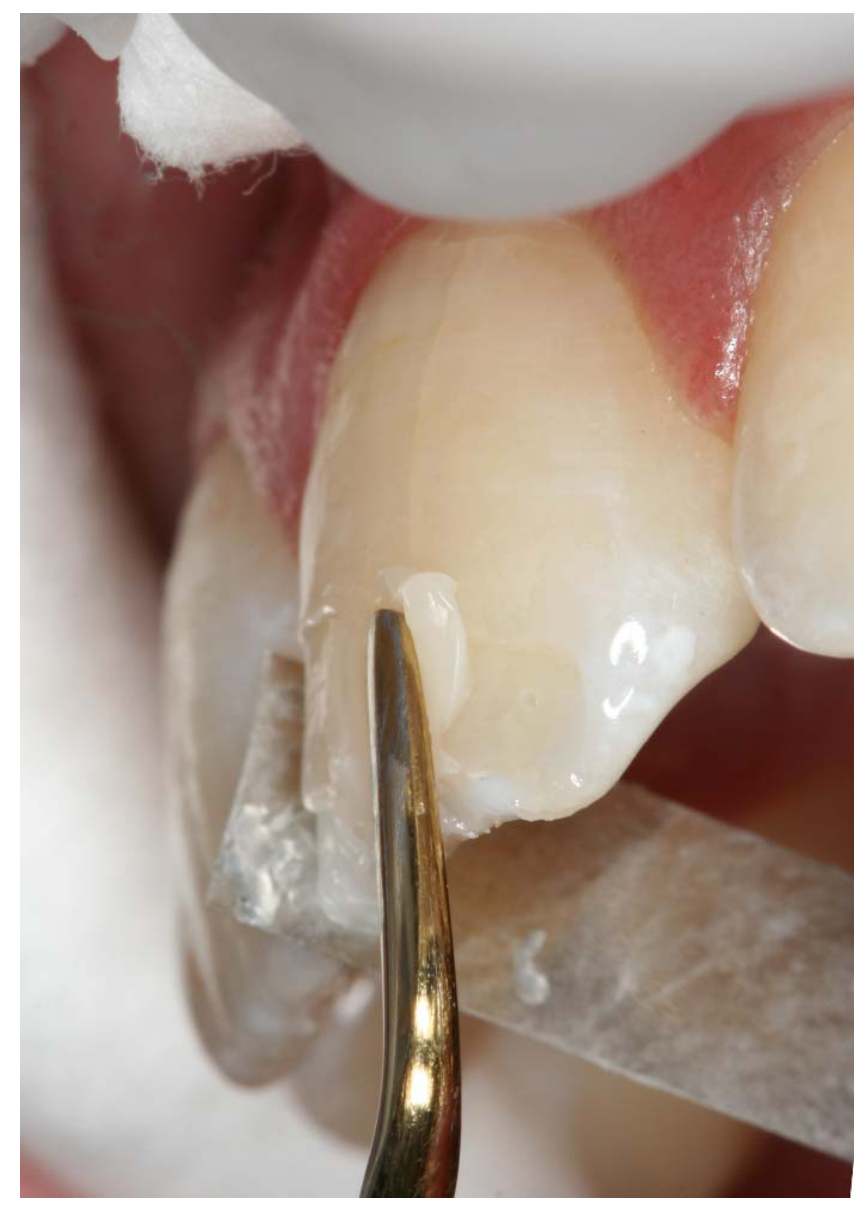

Figure 15-C1

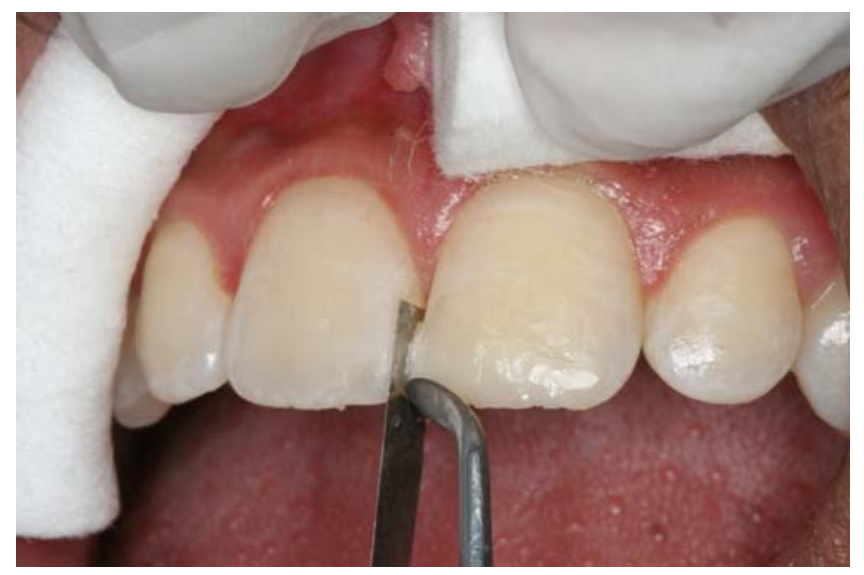

Figure 16-C1

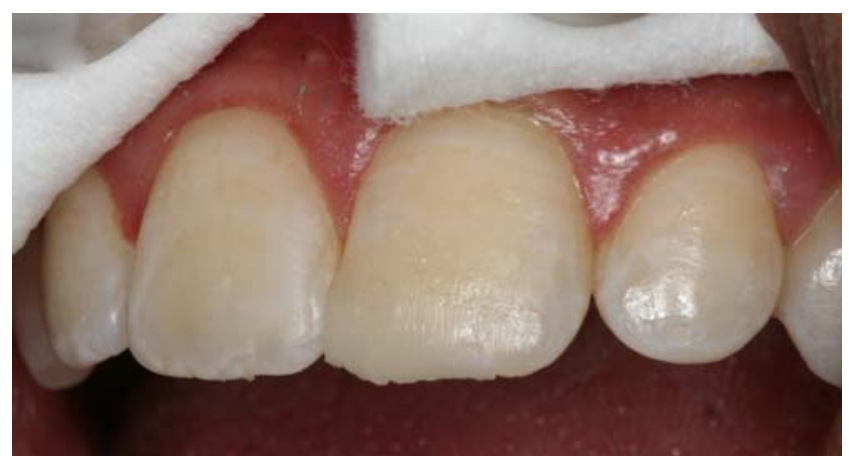

Figure $17-\mathrm{C} 1$

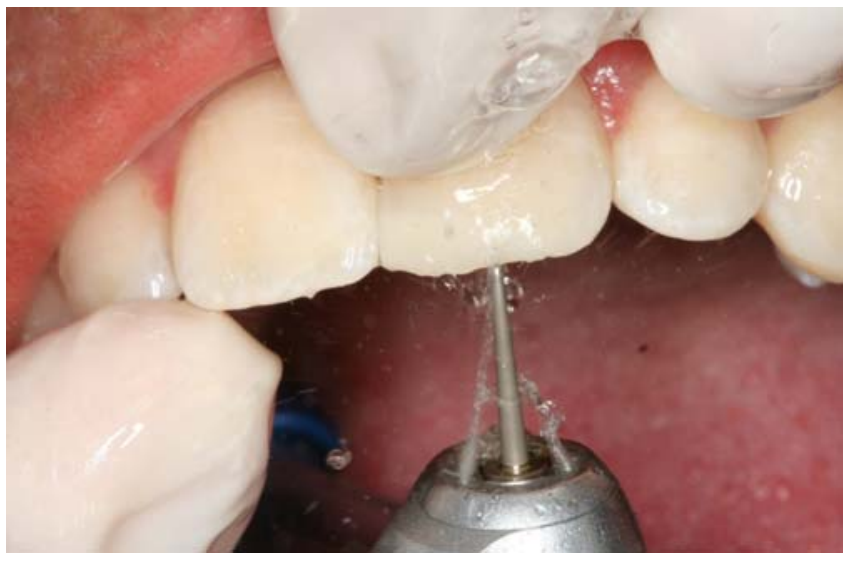

Figure 18-C1

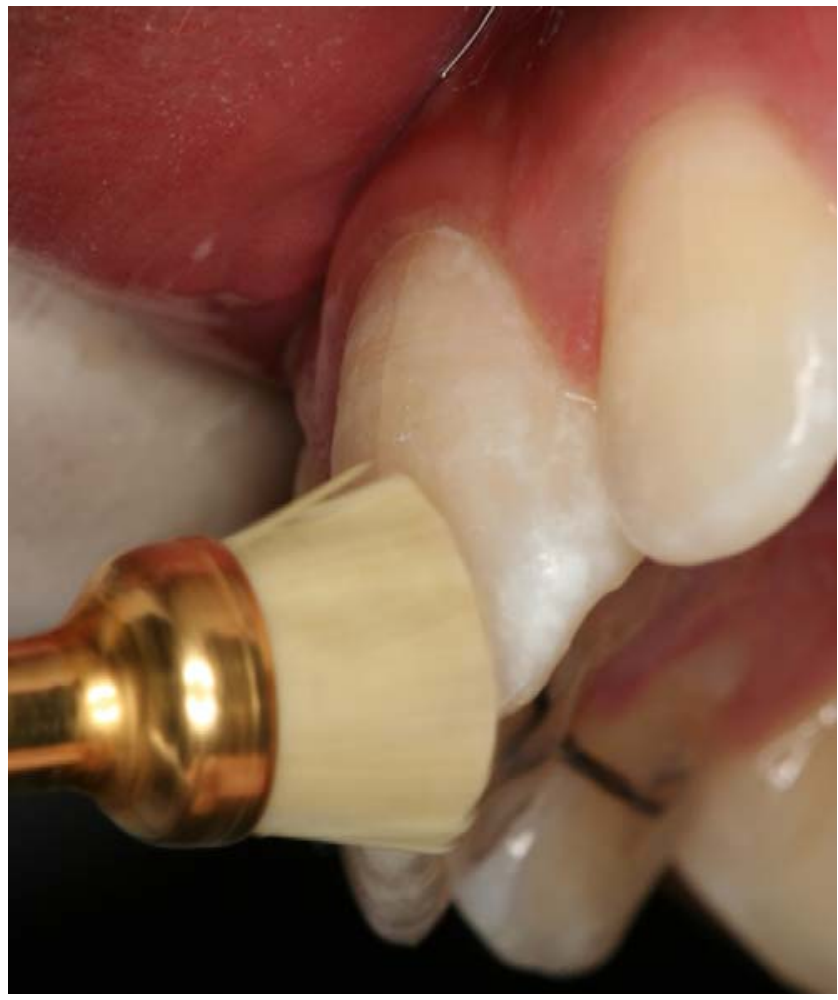

Figure 19-C1

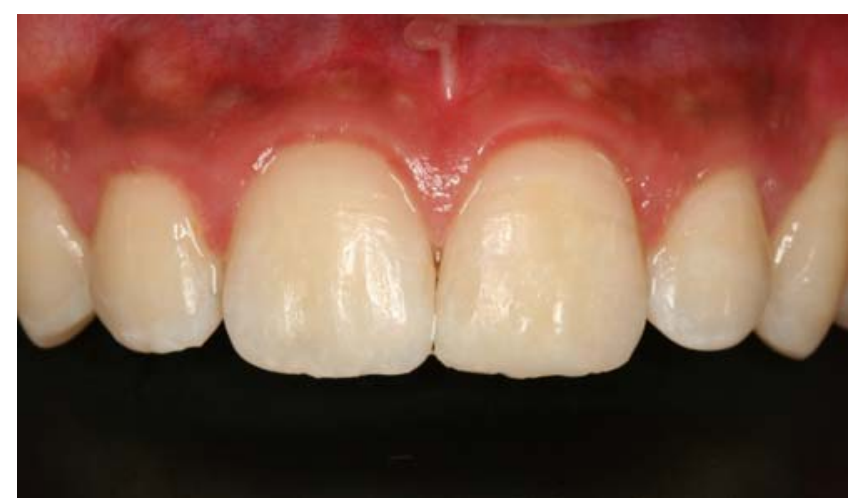

Figure 20-C1 


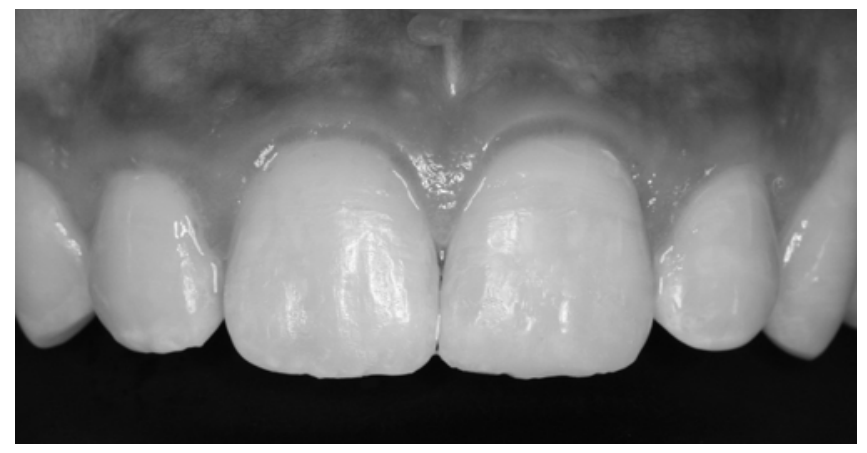

Figure 21-C1

\section{Case 2}

A 20 year-old female patient wanted smile enhancement as she unhappy with the shape of her teeth and the fact that her teeth were hardly visible on smiling (Figure 1-C2).

Direct Composite veneers were planned for 4 anterior teeth using Tetric N-Ceram. Shade was determined to be A2 using the standard vita shade guide. Since the veneer preparation was in the enamel, value is of great importance.

Minimal tooth preparation was done (Figure 2-C2) as in this case more material had to be added, both to allow us enhance the shape of the teeth, alter the incisal edge placement and increase the height of the tooth. Bulk on the labial surface would enhance the lip support and make the smile more pleasing.

Self etching adhesive (Adhese) (Figure 3-C2) was scrubbed on to the tooth for 20 seconds, lightly air thinned and then light cured.

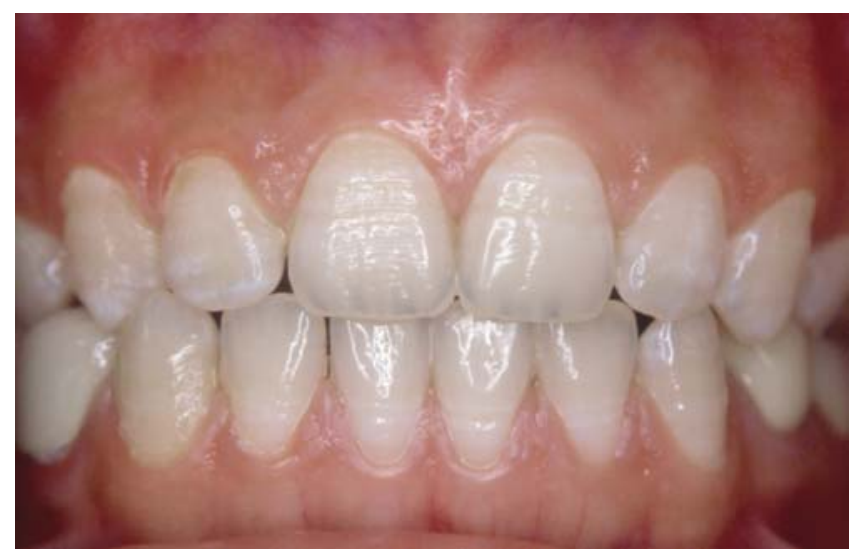

Figure 1-C2

Minimal amount of flowable composite was placed in the line angles of the preparation. The first layer, also called as the adaptive layer was a very thin layer which helped in close contact of composite to the tooth surface. The adaptive layer of Shade A1 (Figure 4-C2) was placed on the entire prepared surface. Next, Shade A3 was sculpted by a cervical contouring instrument to obtain

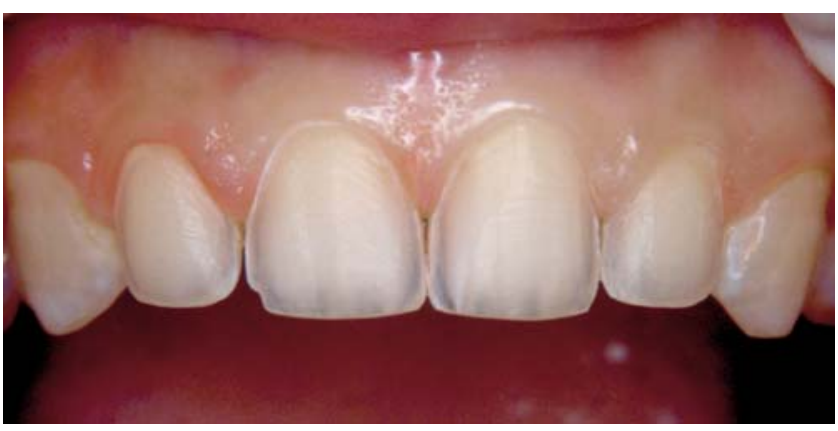

Figure 2-C2

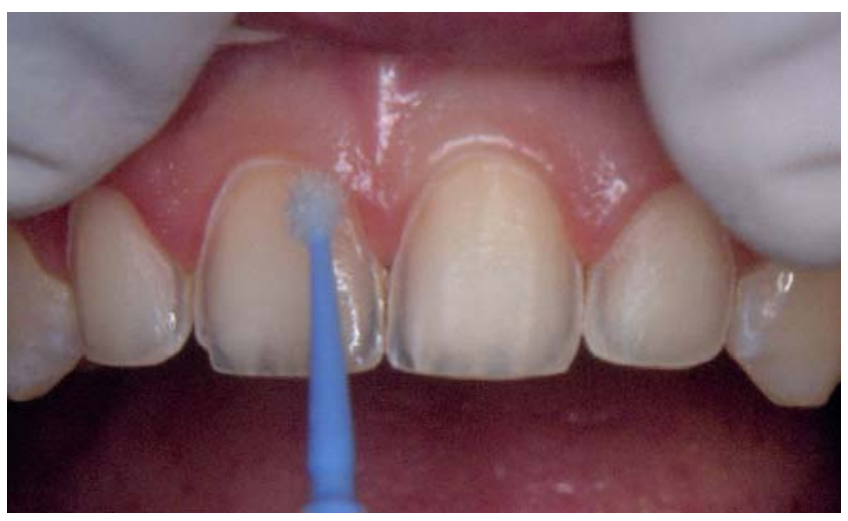

Figure $3-\mathrm{C} 2$

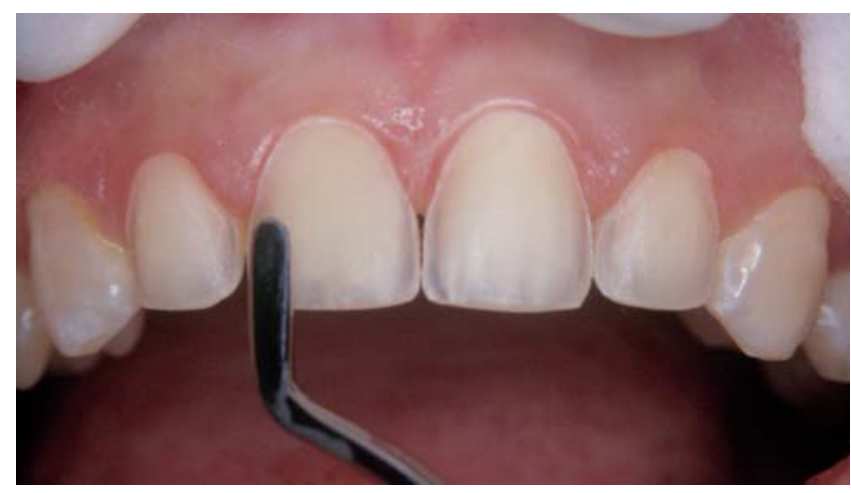

Figure 4-C2

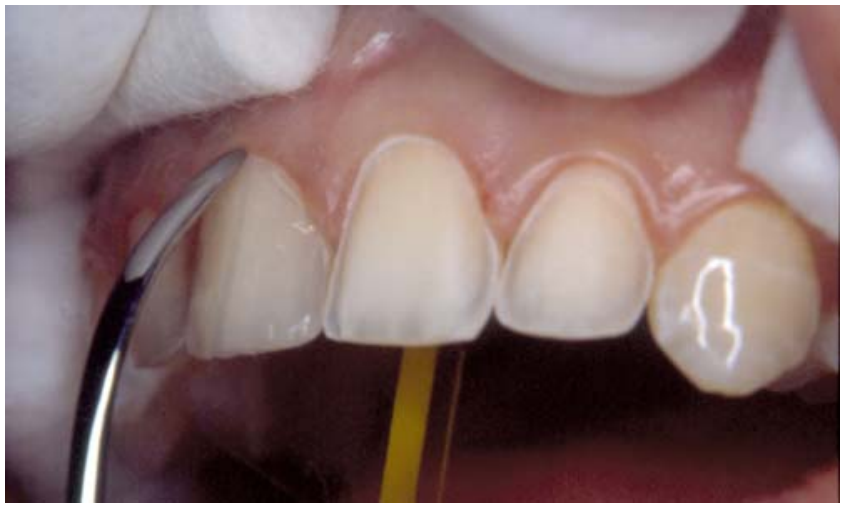

Figure 5-C2

an accurate emergence profile (Figure 5 -C2). This layer extended to the middle of the middle third on the labial surface. Body A2 shade was the next layer placed which blended with the cervical shade and extended beyond 
the incisal edge to form mamelons (Figure 6-C2). To prevent overbuilding of the dentin layer, it was imperative to monitor the thickness of the composite material, in order to allow sufficient space for the enamel layer. This translucent shade of Artemis occupied spaced between the created mamelons and extended up to the cervical area (Figure 7-C2).

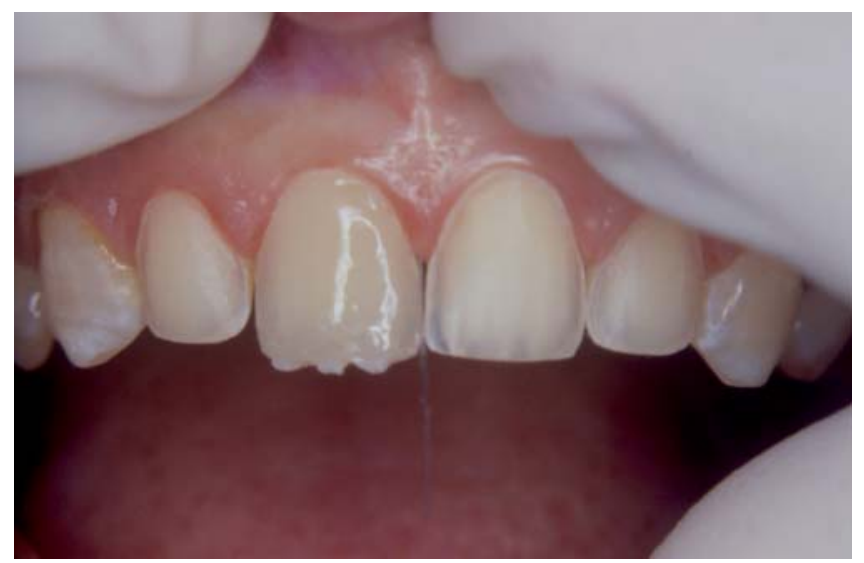

Figure 6-C2

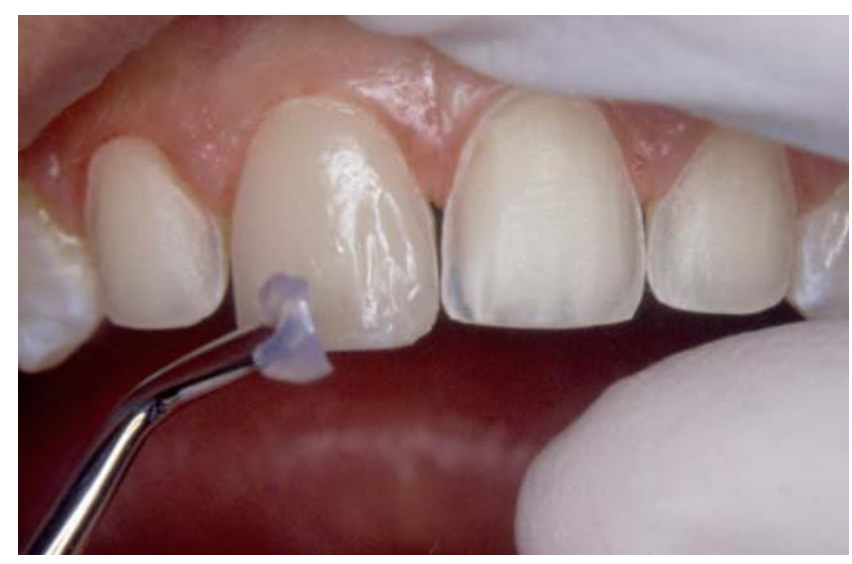

Figure 7-C2

\section{Finishing and polishing}

Finishing focuses on contouring, adjusting, shaping, texturing and smoothing the restoration (Figure 18$\mathrm{C} 1$, Figure $8-\mathrm{C} 2$ ), while polishing concentrates on producing a surface luster (Figure 19-C1) and highly light-reflective surface ${ }^{6}$. For creating texture in finishing, certain areas on the facial surface of the tooth can be highly polished to give a life-like effect to the restoration ${ }^{1,2}$. Eminence of the proximal convexity, the horizontal, vertical ridges, the lobe effect and facial flattening can be effectively projected. The black and white image of the finished restoration shows value of tooth and restoration is similar (Figure 20-C1, 21-C1) (Figure 9-C2,10-C2).

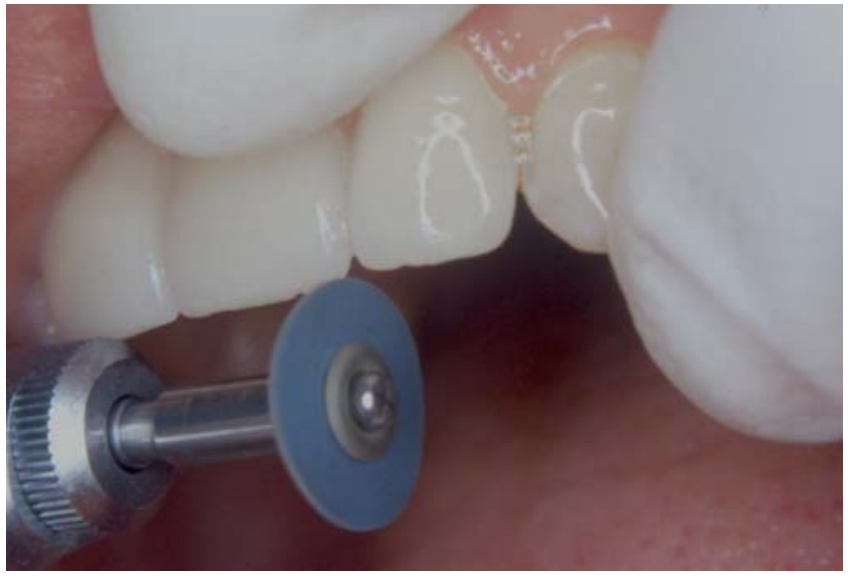

Figure 8-C2

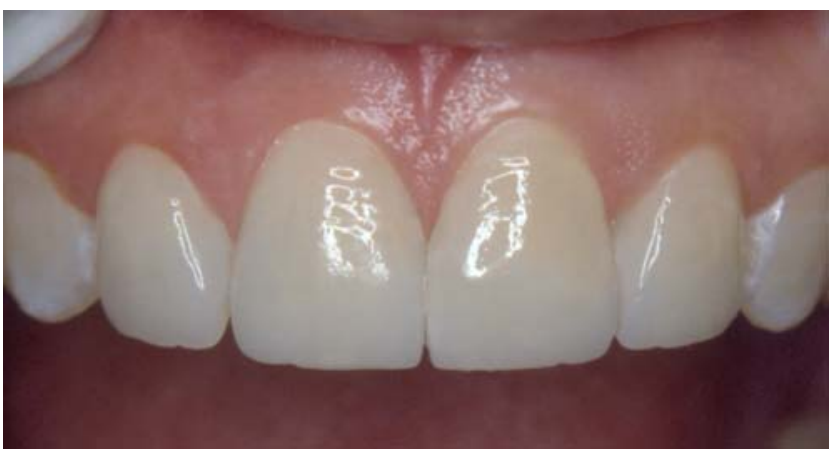

Figure 9-C2

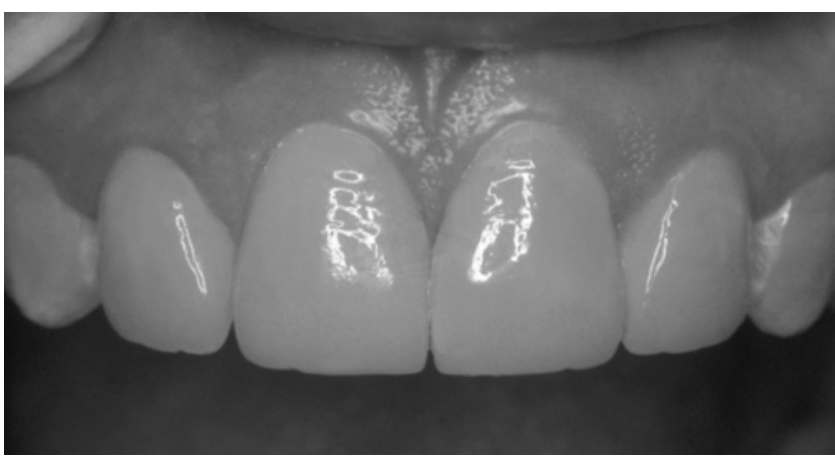

Figure $10-\mathrm{C} 2$

\section{Conclusion}

The success of the anatomic stratification lies largely in the fact that it draws inspiration from the natural layering of dentin and enamel. Continuous technological advances have provided us with materials that can successfully replicate and retain the characteristics built into them while layering them on tooth surfaces. With this concept and technique it is possible for clinicians to provide a more conservative yet functional and aesthetic care to their patients.

\section{References}

1. Rufenacht C. Textbook of Fundamentals of Esthetics. Chicago: Quintessence publishing, 1990, ISBN 0-86715230-3. 
2. Patil RC. Textbook of Esthetic Dentistry: An Artist's Science. PR publications, 2002, ISBN 81-901319-07.

3. Belcheva A. Reconstruction of Fractured Permanent Incisors In Schoolchildren Using Composite Resin BuildUp (Review). Journal of IMAB - Annual Proceeding (Scientific Papers) 2008, book 2.

4. Lesage B. Aesthetic Anterior Composite Restorations: A Guide to Direct Placement. Dent Clin N Am 51 (2007) 359378.

5. Deliperi S, Bardwell D N, Debora M, Kugel G. Layering and Curing techniques for class III restorations: A Two- year Case Report Pract Proced Aesthet Dent $2005 ; 17(3): \mathrm{a}-\mathrm{h}$.

6. Terry D. Restoring the incisal edge. NYSDJ Aug-Sept 2005; 30-35.

7. Kamisha N, Ikeda T, Sano H. Color and translucency of resin composites for layering techniques. Dent Mater J 2005 Sep;24(3):428-32.

8. Esan T A, Bamise C T, Akeredolu P A. Evaluation Of Shade Matching Practices Among Nigerian Dentists Rev Clín Pesq Odontol. 2008 set/dez;4(3):161-168. 